University of Nebraska - Lincoln

DigitalCommons@University of Nebraska - Lincoln

2010

\title{
Public health clinical demonstration project for smoking cessation in veterans with posttraumatic stress disorder
}

Eric A. Dedert

Durham Veterans Affairs Medical Center

Sarah M. Wilson

Durham Veterans Affairs Medical Center

Patrick S. Calhoun

Duke University Medical Center

Scott D. Moore

Duke University Medical Center

Kim W. Hamlett-Berry

Veterans Health Administration

See next page for additional authors

Follow this and additional works at: https://digitalcommons.unl.edu/publichealthresources

Part of the Public Health Commons

Dedert, Eric A.; Wilson, Sarah M.; Calhoun, Patrick S.; Moore, Scott D.; Hamlett-Berry, Kim W.; and Beckham, Jean C., "Public health clinical demonstration project for smoking cessation in veterans with posttraumatic stress disorder" (2010). Public Health Resources. 169.

https://digitalcommons.unl.edu/publichealthresources/169

This Article is brought to you for free and open access by the Public Health Resources at DigitalCommons@University of Nebraska - Lincoln. It has been accepted for inclusion in Public Health Resources by an authorized administrator of DigitalCommons@University of Nebraska - Lincoln. 


\section{Authors}

Eric A. Dedert, Sarah M. Wilson, Patrick S. Calhoun, Scott D. Moore, Kim W. Hamlett-Berry, and Jean C. Beckham 


\title{
Public health clinical demonstration project for smoking cessation in veterans with posttraumatic stress disorder
}

\author{
Eric A. Dedert ${ }^{a, b, c, *}$, Sarah M. Wilson ${ }^{\text {a,b,c }}$, Patrick S. Calhoun ${ }^{a, b, c}$, Scott D. Moore ${ }^{a, b, c}$, \\ Kim W. Hamlett-Berry ${ }^{\mathrm{d}}$, Jean C. Beckham ${ }^{\mathrm{a}, \mathrm{b}, \mathrm{c}}$ \\ a Durham Veterans Affairs Medical Center, 508 Fulton St., 116B, Durham, NC 27705, USA \\ b Department of Psychiatry and Behavioral Sciences, Duke University Medical Center, Box 2969 Medical Center, Durham, NC 27705, USA \\ c Veterans Affairs Mid-Atlantic Region Mental Illness Research, Education, and Clinical Center, Durham, NC 27705, USA \\ ${ }^{d}$ Veterans Health Administration, Public Health Care Strategic Health Care Group, 810 Vermont Avenue NW, Washington, DC 20420, USA
}

\section{A R T I C L E I N F O}

\section{Keywords:}

Smoking

Posttraumatic stress disorder

Military veterans

Public health

Telehealth

\begin{abstract}
A B S T R A C T
Veterans with posttraumatic stress disorder are at high risk for smoking and experience difficulty with smoking cessation. We designed this clinical demonstration project to provide a low-cost, feasibly implemented smoking cessation intervention that would maximize the number of smokers who accessed the intervention. Five hundred eighty-four veteran smokers were contacted by invitational letters. Interested veterans received follow-up telephone calls using standardized scripts offering three intervention resources: 1) a referral to the National Cancer Institute's Smoking Quitline, 2) web-based counseling, and 3) local Veteran Affairs pharmacologic treatment for smoking cessation. Twenty-three percent of survey recipients participated in the clinical program. Two months after these resources were offered by phone, follow-up phone calls indicated that $25 \%$ of participants providing follow-up information reported maintaining smoking abstinence. This clinical demonstration project was associated with a $2.6 \%$ impact (i.e., reach [31.1\% of smokers accessed intervention] by efficacy [ $8.4 \%$ of those accessing intervention quit]), meaning that $2.6 \%$ of the total number of targeted smokers reported 8 week abstinence. Results suggested that this brief, lowcost intervention was feasible and promoted smoking cessation in veterans with posttraumatic stress disorder.
\end{abstract}

(c) 2009 Elsevier Ltd. All rights reserved.

\section{Introduction}

Smoking is a significant concern in military personnel and veterans. Studies have shown that some military personnel begin smoking while deployed and those who already smoke increase their cigarette consumption (Collie, Clancy, Yeatts, \& Beckham, 2004; Forgas, Meyer, \& Cohen, 1996). A survey of veterans receiving care from the Veterans Health Administration (VHA) reports a smoking prevalence rate of $22.2 \%$ (VHA, 2008). Among veterans returning from Iraq and Afghanistan the reported rate is $24 \%$ (Acheson, StraitsTroster, Calhoun, Beckham, \& Hamlett-Berry, submitted for publication). These rates are higher than recent estimates of smoking rates in the general United States population (21\%) (Centers for Disease Control \& Prevention, 2006).

Smoking is even more prevalent among individuals with psychiatric disorders. Population-based data suggest that, while only $23 \%$ of individuals without a psychiatric disorder are smokers, $45 \%$ of those

\footnotetext{
* Corresponding author. Durham Veterans Affairs Medical Center, 508 Fulton St. (116 B), Durham, NC 27705, USA. Tel.: +1 919286 0411x5526; fax: +1 9194165922. E-mail address: Eric.Dedert@duke.edu (E.A. Dedert).
}

with posttraumatic stress disorder (PTSD) smoke (Lasser et al., 2000). In an epidemiologic sample, individuals with PTSD (non-combat related) were at increased risk of smoking, with an odds ratio of 4.03 (Breslau, Davis, \& Schultz, 2003). In addition, smokers with PTSD tend to smoke more heavily than smokers without PTSD (Beckham et al., 1997). Although smoking is prevalent in veterans with PTSD, many report interest in quitting smoking, with $50 \%$ contemplating quitting smoking and another $21 \%$ preparing to make a quit attempt (Kirby et al., 2008). However, smokers with PTSD have low cessation rates, with several studies suggesting that low cessation rates are due to smoking that is cued by PTSD symptoms (for review, see Fu et al., 2007). Approaches to improving care and access for smokers with PTSD may be particularly useful considering the tendency for psychiatric groups to be socially isolated (Schroeder, 2008) and undertreated for smoking cessation (Prochaska \& Velicer, 2004). While traditional medical models focus on the content of the most efficacious program, public health models address access to care by focusing on reach (i.e., number veterans who receive an intervention) as well as the efficacy of an intervention (Abrams et al., 1996).

Although smoking cessation resources are available, previous data suggest that relatively few veteran smokers received prescriptions for smoking cessation aides (Jonk et al., 2005). Additionally, specialty 
smoking cessation clinics are limited by poor attendance rates (Volpp et al., 2006). Perhaps as a result, only $17 \%$ of veteran smokers in the VHA report receiving desired cessation treatment in the previous year (Miller et al., 2001). For smoking rates to significantly decline at the population level, it is critical to improve the reach of interventions and promote access to care. These aims could be addressed by utilizing portable telephone- or web-based interventions, which are increasingly utilized by smokers and have demonstrated promising efficacy (Graham, Cobb, Raymond, Sill, \& Young, 2007; Joseph \& An, 2004; Volpp et al., 2006; Zhu et al., 2002).

A promising approach to improving reach was reported in a project (Beckham et al., 2008) contacting veterans returning from Iraq or Afghanistan with letters offering existing VHA smoking cessation resources, including the National Cancer Institute's smoking cessation Quitline (1-877-44U-QUIT) and mail-out of nicotine replacement (Beckham et al., 2008). Results suggested that the intervention was feasible and assisted those veterans who participated in quitting smoking. The purpose of the current clinical demonstration project was to evaluate this approach in veterans with PTSD. Secondarily, the addition of an internet based intervention QuitNet ${ }^{\circledR}$ (www.QuitNet. com) was also included in the second cohort to evaluate its feasibility in this veteran group.

\section{Methods}

\subsection{Sample}

The target population of 584 veterans included two cohorts of veterans with PTSD drawn from the medical record database for veterans registered with the Durham, NC, Veterans Affairs (VA) Medical Center and screened positive for tobacco. The first cohort was recruited from the outpatient VA PTSD Clinic and included veterans with PTSD from multiple eras (e.g., Korean War, Vietnam War, Gulf War, etc.). The second cohort included veterans who served during the Iraq and Afghanistan conflicts and had the International Classification of Diseases code (World Health Organization, 2004) for PTSD on their problem list.

\subsection{Program components}

The intervention was based on a previously published program (Beckham et al., 2008). It included the National Cancer Institute's Smoking Quitline telephone counseling and pharmacotherapy, consisting of access to bupropion, nicotine patches, and one nicotine replacement "rescue" method (nicotine gum, lozenge, or inhaler). In the second cohort only, telephone counseling and pharmacotherapy components were supplemented by free web-based smoking cessation provided by QuitNet ${ }^{\circledR}$ (www.quitnet.com). QuitNet ${ }^{\circledR}$ provides cessation treatment in accordance with national guidelines (Fiore et al., 2008).

\subsection{Contact procedure}

To establish contact, up to four sequenced letters were mailed using procedures recommended by the standardized Dillman system (Dillman, 1978, 2000): respondent-friendly questionnaire, up to four total contacts, prepaid return envelope, personalized correspondence including official stationery, personalized salutation, and a real signature. The brief letter included eight questions to determine smoking status, smoking history, and program interest. A total of 330 initial letters were mailed to the first cohort between February and March 2006, and 254 were mailed to the second cohort between October and November 2007. In the first cohort, smokers who did not return surveys were contacted by phone. Prior to contacting the second cohort, the clinical procedures were modified to remove follow-up calls to smokers who did not return surveys to increase the feasibility of the intervention and focus on veterans who responded to surveys.

All smokers who returned the mail-out survey were contacted by telephone by project personnel who used brief scripts to introduce Quitline, QuitNet ${ }^{\circledR}$, and pharmacological components. Smokers interested in medications completed screening to determine the presence of any medication contraindications. In cases with no contraindications, nicotine replacement was prescribed and mailed to the veteran through the VA pharmacy. When available, the veteran's psychiatrist was informed of the patient's intention to make a smoking cessation attempt and consulted to determine appropriateness of bupropion prescription. Patients' psychiatrists were contacted via email to elicit input regarding the safety of adding Zyban to the smokers' prescriptions. Medications were accompanied by information on side effects and administration instructions.

This project was evaluated using follow-up telephone calls that were completed eight weeks after the final intervention contact with project personnel. Those who participated in the program received a follow-up phone contact eight weeks after contact with VA personnel and asked about quit attempts and smoking abstinence.

\section{Results}

Because the second cohort introduced the used of free web-based counseling and eliminated phone calls to smokers who did not return initial surveys, results are initially presented separately in the narrative below to facilitate comparisons between cohorts. However, due to the substantial overlap in procedures used for the two cohorts, including the Dillman method for contacting target smokers and the Quitline and pharmacotherapy program components, we also present totals aggregated across both groups in Table 1, in addition to results for the individual cohorts. Patient flow from the initial target group to those participating in the intervention for both cohorts is illustrated in Figs. 1 and 2.

\subsection{First cohort: descriptive statistics of project procedures}

A total of 330 initial letters were mailed and 23 (7\%) were returned with an incorrect address. A total of 169 (51\%) responded by returning one of the surveys, calling project personnel, or appearing in person. Because 33 veterans who spoke with project personnel reported no longer smoking, the target population of current smokers was reduced from 330 to 297. Of the current smokers, a total of 45 (15\%) responded to the survey but were subsequently unavailable by phone, resulting in a total of 103 (35\%) veteran smokers who responded to the survey and accessed the intervention by speaking with project personnel. An additional 26 (9\%) veterans who did not respond to surveys were successfully contacted by telephone, resulting in a total of 129 (43\%) who accessed the intervention. The remaining 127 (43\%) veterans did not respond to any surveys and were unavailable by phone. Of the 129 accessing the intervention, 37 (29\%) indicated no interest in smoking cessation. Of the remaining 92 who were assisted, 90 (98\%) indicated interest in phone counseling and were referred to the Quitline. Ninety-four (85\%) reported interest in pharmacotherapy.

Table 1

Eight week follow-up data for both cohorts.

\begin{tabular}{llrr}
\hline & $\begin{array}{l}\text { First cohort } \\
(N=36)\end{array}$ & $\begin{array}{l}\text { Second cohort } \\
(N=19)\end{array}$ & \multicolumn{1}{l}{$\begin{array}{l}\text { Total } \\
(N=55)\end{array}$} \\
\hline Used Quitline & $12(33 \%)$ & $6(32 \%)$ & $18(33 \%)$ \\
Used QuitNet & - & $8(42 \%)$ & $8(42 \%)$ \\
Set a quit date & $18(50 \%)$ & $12(63 \%)$ & $30(55 \%)$ \\
Quit attempt $>$ 24h & $18(50 \%)$ & $11(58 \%)$ & $29(53 \%)$ \\
Abstinent at follow-up & $8(22 \%)$ & $6(32 \%)$ & $14(25 \%)$ \\
\hline
\end{tabular}




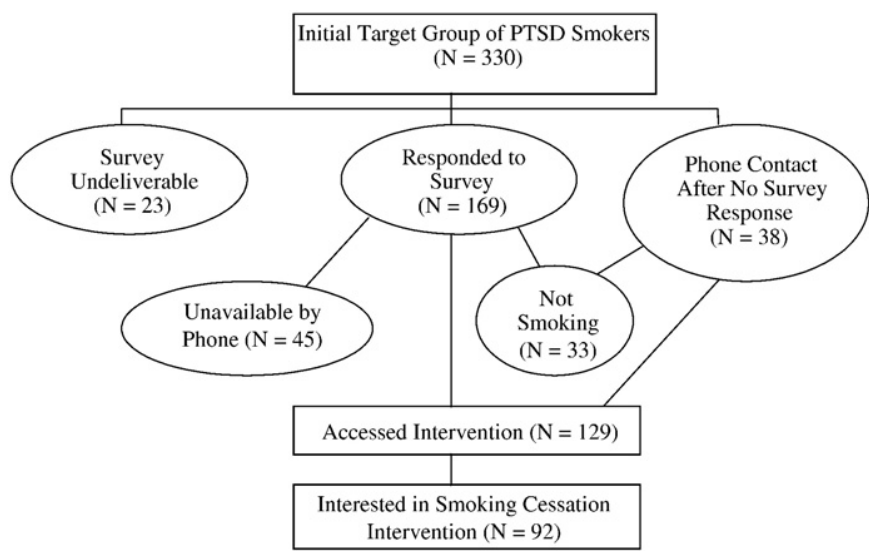

Fig. 1. Summary of intervention process for first cohort. The figure illustrates how many veterans accessed the intervention by speaking with project personnel, as well as factors that prevented veterans from accessing the intervention.

\subsection{First cohort: project evaluation}

Eight week follow-up data are presented in Table 1. Of the 92 veterans assisted by the intervention, 36 were available for eight week follow-up contacts. Twelve (33\%) smokers reported contacting Quitline. Eighteen (50\%) smokers reported making a quit attempt between the intervention and follow-up contacts, with eight (22\%) remaining smoke-free at the time of the follow-up. Of the initial target group of 297 smokers in this cohort, 129 accessed the intervention by discussing program components with project personnel, meaning the reach for this cohort was $43.4 \%$. Of the smokers accessing the intervention, eight reported smoking abstinence at the eight week follow-up contact, for an efficacy of $6.2 \%$. The impact rate for this cohort was $2.7 \%$.

\subsection{Second cohort: descriptive statistics of project procedures}

A total of 254 initial letters were mailed and seven (3\%) were returned with an incorrect address. Of these veteran smokers, 62 (24\%) responded to surveys. Because seventeen veterans who spoke with project personnel reported no longer smoking, the target population of current smokers was reduced from 254 to 237. Of the 45 smokers who responded to the survey, eight (3\%) were

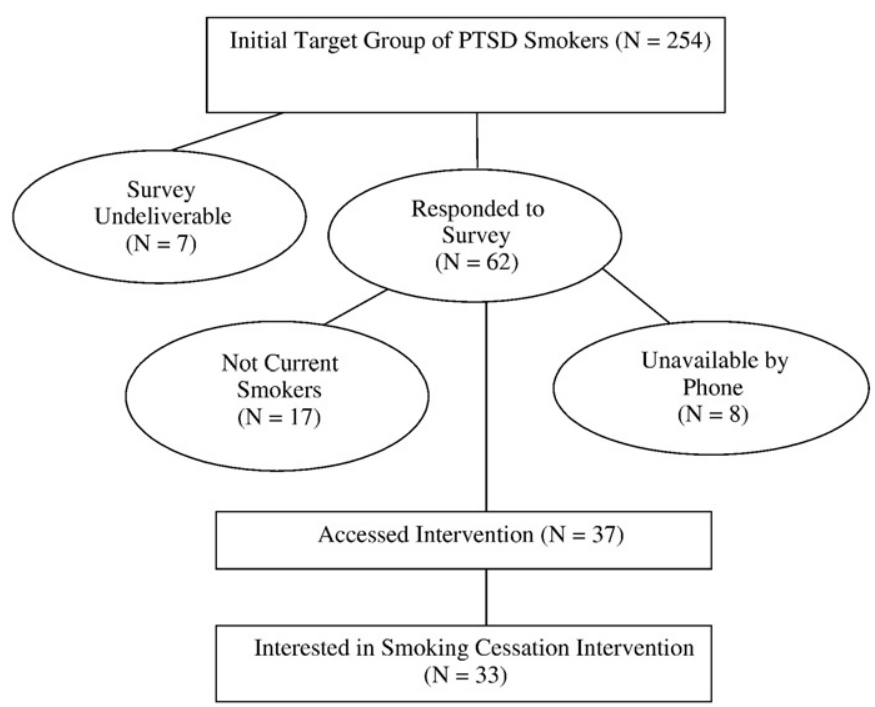

Fig. 2. Summary of intervention process for second cohort. The figure illustrates how many veterans accessed the intervention by speaking with project personnel, as well as factors that prevented veterans from accessing the intervention. subsequently unavailable by phone, resulting in a total of 37 (16\%) smokers who accessed the intervention. Of the 37 accessing the intervention, four (11\%) indicated no interest in smoking cessation. Of the remaining 33 who were assisted, twenty-five (76\%) indicated interest in phone counseling and were referred to the Quitline. Seventeen (52\%) reported interest in pharmacotherapy. Web-based counseling was offered only to the second cohort, and 24 (73\%) veterans reported interest in web-based counseling and were referred to QuitNet ${ }^{\mathbb{B}}$. Those who had access to an internet connection at the time of the intervention contact were assisted in signing up for a membership by research personnel. Other veterans interested in webbased counseling were mailed a flier with instructions for signing up for a free membership to QuitNet ${ }^{\circledR}$.

\subsection{Second cohort: project evaluation}

Table 1 presents eight week follow-up data for the second cohort along with data from the first cohort. Of the 32 veterans assisted by the intervention, 19 were available for eight week follow-up contacts. Six (32\%) smokers reported contacting Quitline and eight (42\%) reported using QuitNet ${ }^{\circledR}$. Eleven (58\%) smokers reported making a quit attempt between the intervention and follow-up contacts, with six (32\%) remaining smoke-free at the time of follow-up. Of the initial target group of 237 smokers in this cohort, 37 accessed the intervention by discussing program components with project personnel, meaning the reach for this cohort was $15.6 \%$. Of the smokers accessing the intervention, six reported smoking abstinence at the eight week follow-up contact, for an efficacy of $16.2 \%$. The impact rate for this cohort was $2.5 \%$.

\section{Discussion}

This project demonstrated that the impact of the approach (lowcost telephone and web-based care with invitational letters) was associated with a $2.6 \%$ impact rate. This is a favorable response compared to typical smoking cessation public health approaches with results that suggest an impact rate of approximately $1 \%$ (An et al., 2006; Cummings et al., 2006).

There was a relatively low undeliverable survey rate $(5 \%)$ in the current project, likely because veterans registered for treatment at the VA typically update their mailing addresses as part of their clinical care. The proportion of smokers completing the mail survey (42\%) was relatively high, suggesting high interest in smoking cessation resources. Consistent with this observation, the smokers who responded to the survey were generally interested in the available resources. This clinical demonstration engaged 125 smokers in smoking cessation efforts. As a result, this project improved the reach of existing clinical efforts addressing smoking cessation.

Based on follow-up data, of those who responded to invitation letters and talked to project personnel, 55\% set a quit date. Eight weeks after the final contact with project personnel, $25 \%$ were abstinent from tobacco. Combined with the quit rate (38\%) in our previous efforts with a similar protocol (Beckham et al., 2008), preliminary evidence suggests the potential for short-term efficacy of this intervention. This is consistent with clinical practice guidelines indicating that brief interventions, such as the one described in this report, effectively promote smoking cessation (Fiore et al., 2008).

Comparing reach for cohorts within this project, the higher response rate in the PTSD clinic cohort could have been attributable to patients' regular clinic visits, as opposed to the second cohort, which consisted of registered veterans with a range of visit frequency. In contrast, abstinence rates from the second cohort suggest that the addition of QuitNet ${ }^{\circledR}$ might have increased the efficacy. In terms of impact, this clinical demonstration project was associated with a $2.6 \%$ impact (i.e., reach [31.1\% of smokers accessed intervention] by efficacy [ $8.4 \%$ of those accessing intervention quit]). 
A previous report on this intervention initially targeted 1500 veterans, without information on how many were smokers (Beckham et al., 2008). Assuming a smoking rate of $22.2 \%$ in veterans (VHA, 2008), this previous report targeted 333 smokers. A total of 31 smokers accessed the intervention, for a reach of $9 \%$. Of these, nine reported smoking abstinence, for an efficacy of $29 \%$, yielding an impact of $2.7 \%$. As a result, the impact from the current report is slightly lower than the estimated impact from the previous report. The similar rates observed in this report compared to the previous report (Beckham et al., 2008) are noteworthy because the sample in this project were PTSD smokers, suggesting that this approach may be as potentially useful in PTSD smokers.

Because there was no control group of smokers to use for comparison in this study, it is difficult to determine what the rate of smoking cessation would have been during the eight week intervention, which we will refer to as spontaneous smoking cessation. In studies following smokers who were not assessed for psychiatric disorders for three to five years, a range of 8 to $13 \%$ of smoking cessation was observed (Lennox \& Taylor, 1994; Osler, Prescott, Hein, \& Schnohr, 1999; Wagenknecht et al., 1993). Based on these observations, it appears that a small but significant number of smokers spontaneously quit smoking over a period of several years. However, the number of veteran smokers with PTSD who would be expected to quit over a brief time period, such as the eight weeks used in our project, is likely quite small. Some information can be gleaned from using historical quit rates from our sample of smokers, who reported on the initial questionnaire whether they were still smoking and the time since their most recent cigarette. Using this information for the 584 patients returning the questionnaire, only one patient $(0.2 \%)$ reported successfully quitting smoking in the month prior to completing the questionnaire. Based on self-report, it appears that the smokers targeted by this intervention had higher quit rates during the intervention, relative to the month prior to the intervention. Future research could address this issue more directly.

This project was also limited by low follow-up rates, the absence of biological verification of smoking abstinence and non-experimental design of the approach. Low follow-up rates may have been due to a lack of payment for follow-up completion (which is usually present in research studies). Based on the promising smoking cessation rates in this project, randomized research using a biological verification method focused on further evaluation of this public health initiative is warranted.

Despite these limitations, this report contributed to the evidence supporting the use of public health approaches to reduce smoking in veterans, including those with PTSD. These approaches can be low cost, increase both reach and impact, and may help reduce the health care costs and improve quality of life in veterans.

\section{Acknowledgements}

We would like to thank the veterans who participated in this clinical project. This work was primarily supported by the VA Public Health Strategic Health Care Group. It was also supported by the MidAtlantic MIRECC and the Office of Research and Development Clinical Science, Department of Veterans Affairs, and by 2K24DA016388, 2R01CA081595, 3R01CA81595-07S1 and R21DA019704. Dr. Dedert completed clinical contacts and participated in the writing and editing of this manuscript. Ms. Wilson participated in the management of the project and writing of the manuscript. Drs. Calhoun and Beckham participated in project design and writing of the manuscript. Dr. Moore participated in project design, providing pharmacotherapy, and writing of the manuscript. Dr. Hamlett-Berry participated in writing of the manuscript. The views expressed in this manuscript are those of the authors and do not necessarily represent the views of the funding agencies. The authors do not have any competing interests that might be interpreted as influencing the research.

\section{References}

Abrams, D. B., Orleans, C. T. Niaura, R. S. Goldstein, M. G. Prochaska, J. O., \& Velicer, W. (1996). Integrating individual and public health perspectives for treatment of tobacco dependence under managed health care: A combined stepped care and matching model. Annals of Behavioral Medicine, 18, 290-304.

Acheson, S.K., Straits-Troster, K., Calhoun, P.S., Beckham, J.C., \& Hamlett-Berry, K. Characteristics and correlates of tobacco use among U.S. veterans returning from Iraq and Afghanistan. Unpublished results.

An, L. C., Schillo, B. A., Kavanaugh, A. M., Lachter, R. B. Luxenberg, M. G., Wendling, A. H., et al. (2006). Increased reach and effectiveness of a statewide tobacco quitline after the addition of access to free nicotine replacement therapy. Tobacco Control, 15, 286-293.

Beckham, J. C., Kirby, A. C., Feldman, M. E., Hertzberg, M. A., Moore, S. D., Crawford, A. L. et al. (1997). Prevalence and correlates of heavy smoking in Vietnam veterans with chronic posttraumatic stress disorder. Addictive Behaviors, 22, 637-647.

Beckham, J. C., Becker, M. E., Hamlett-Berry, K. W., Drury, P., Kang, H. K., Wiley, M. T., et al. (2008). Preliminary findings from a clinical demonstration project for veterans returning from Iraq or Afghanistan. Military Medicine, 173, 448-451.

Breslau, N., Davis, G. C., \& Schultz, L. R. (2003). Posttraumatic stress disorder and the incidence of nicotine, alcohol, and other drug disorders in persons who have experienced trauma. Archives of General Psychiatry, 60, 289-294.

Centers for Disease Control and Prevention (2006). Targeting tobacco use: The nation's leading cause of death, at a glance, 2006.

Collie, C. F., Clancy, C. P., Yeatts, B., \& Beckham, J. C. (2004). Posttraumatic stress disorder and smoking cessation in veteran smokers. Journal of Trauma Practice, 3, 37-63.

Cummings, K. M., Fix, B., Celestino, P., Carlin-Menter, S., O'Connor, R., \& Hyland, A (2006). Reach, efficacy, and cost-effectiveness of free nicotine medication giveaway programs. Journal of Public Health Management Practice, 12, 37-43.

Dillman, D. A. (1978). Mail and telephone surveys: The total design method. New York: Wiley.

Dillman, D. A. (2000). Mail and Internet surveys: The tailored design method. New York: John Wiley \& Sons.

Fiore, M. C., Jaen, C. R., Baker, T. B., Bailey, W. C., Benowitz, N., Curry, S. J., et al. (2008) Treating tobacco use and dependence: 2008 update.

Forgas, L., Meyer, D., \& Cohen, M. (1996). Tobacco use habits of naval personnel during Desert Storm. Military Medicine, 161, 165-168.

Fu, S., McFall, M., Saxon, A. J., Beckham, J. C., Carmody, T. P., Baker, D. G., et al. (2007). Posttraumatic stress disorder and smoking: A systematic review. Nicotine E Tobacco Research, 9, 1071-1084.

Graham, A. L., Cobb, N. K., Raymond, L., Sill, S., \& Young, J. (2007). Effectiveness of an Internet-based worksite smoking cessation intervention at 12 months. Journal of Occupational and Environmental Medicine, 49, 821-828.

Jonk, Y. C., Sherman, S. E., Scott, E., Steven, S., Hamlett-Berry, K. W., Geraci, M. C., et al (2005). National trends in the provision of smoking cessation aids within the Veterans Health Administration. American Journal of Managed Care, 11, 77-85.

Joseph, A. M., \& An, L. C. (2004). Telephone care for smoking cessation in the Department of Veterans Affairs. Paper presented at the Building on Success in Smoking Cessation, San Francisco, $C A$.

Kirby, A. C., Hertzberg, B. P., Collie, C. F., Yeatts, B., Dennis, M. F., McDonald, S. D., et al (2008). Smoking in help-seeking veterans with PTSD returning from Afghanistan and Iraq. Addictive Behaviors, 33, 1448-1453.

Lasser, K., Boyd, J. W., Woolhander, S., Himmelstein, D. U., McCormick, D., \& Bor, D. H. (2000). Smoking and mental illness: A population-based prevalence study. Journal of the American Medical Association, 284, 2606-2610.

Lennox, A. S., \& Taylor, R. J. (1994). Factors associated with outcome in unaided smoking cessation, and a comparison of those who have never tried to stop smoking with those who have. British Journal of General Practice, 44, 245-250.

Miller, D., Kalman, D., Ren, X. S., Lee, A. F., Niu, Z., \& Kazis, L. (2001). Health behaviors of veterans in the VHA: Tobacco abuse: 1999 large health survey of VHA enrollees.

Osler, M., Prescott, E., Hein, H., \& Schnohr, P. (1999). Gender and determinants of smoking cessation. A longitudinal study of Danish smokers, preventive medicine (pp. 57-62).

Prochaska, J., \& Velicer, W. (2004). Integrating population smoking cessation policies and programs. Public Health Reports, 119, 244-252.

Schroeder, S. (2008). Stranded in the periphery - The increasing marginalization of smokers. New England Journal of Medicine, 358, 2284-2286.

Veterans Health Administration (2008). Office of the Assistant under the Deputy for Health Policy and Planning: 2007 survey of veteran enrollees' health and reliance upon VA.

Volpp, K. G., Gurmankin Levy, A., Asch, D. A., Berlin, J. A., Murphy, J. J., Gomez, A., et al. (2006). A randomized controlled trial of financial incentives for smoking cessation. Cancer Epidemiology, Biomarkers \& Prevention, 15, 12-18.

Wagenknecht, L. E., Manolio, T. A., Lewis, C. E., Perkins, L. L., Lando, H. A., \& Hulley, S. B. (1993). Race and education in relation to stopping smoking in the US: The CARDIA study. Tobacco Control, 2, 286-292.

World Health Organization (2004). International statistical classification of diseases and related health problems, 10th revision, Second Edition Geneva: WHO.

Zhu, S. H., Anderson, C. M., Tedeschi, G. J., Rosbrook, B., Johnson, C. E., Byrd, M., et al. (2002). Evidence of real-world effectiveness of a telephone quitline for smokers. New England Journal of Medicine, 347, 1087-1093. 